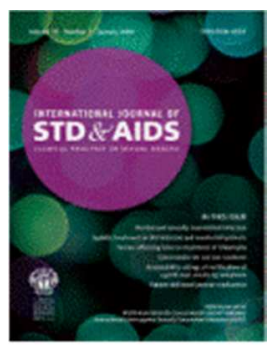

\title{
Predictors identifying those at increased risk for STDs: a theory-guided review of empirical literature and clinical guidelines
}

\begin{tabular}{|r|l|}
\hline Journal: & International Journal of STD \& AIDS \\
\hline Manuscript ID: & IJSA-14-178.R1 \\
\hline Manuscript Type: & Review Articles \\
\hline Date Submitted by the Author: & $17-$ Sep-2014 \\
\hline Complete List of Authors: & $\begin{array}{l}\text { Falasinnu, Titilola; University of British Columbia, School of Population and } \\
\text { Public Health } \\
\text { Ogilvie, Gina; University of British Columbia, } \\
\text { Gilbert, Mark; British Columbia Centre for Disease Control, Clinical } \\
\text { Prevention Services; University of British Columbia, Faculty of Medicine } \\
\text { Shoveller, Jean; University of British Columbia, } \\
\text { Hottes, Travis; British Columbia Centre for Disease Control, Clinical } \\
\text { Prevention Services } \\
\text { Gustafson, Paul; University of British Columbia, }\end{array}$ \\
\hline Keyword: & $\begin{array}{l}\text { Chlamydia (Chlamydia trachomatis) < Bacterial disease, Epidemiology < } \\
\text { Other, Screening < Other, Sexual behaviour < Other, Gonorrhea (Neisseria } \\
\text { gonorrhoeae) < Bacterial disease }\end{array}$ \\
\hline
\end{tabular}

\section{SCHOLARONE ${ }^{\text {IN }}$ \\ Manuscripts}




\section{Title Page}

\section{Manuscript title:}

Predictors identifying those at increased risk for STDs: a theory-guided review of empirical literature and clinical guidelines

\section{Type of article:}

Review

\section{Authors' full names, highest academic degrees, and affiliations:}

1. Name: Titilola Falasinnu

- Highest academic degree(s): Master of Health Science (MHS)

- Affiliation: The School of Population and Public Health, University of British Columbia

2. Name: Mark Gilbert

- Highest academic degree(s): Doctor of Medicine (MD); Master of Science (MSc)

- Affiliation: British Columbia Centres for Disease Control

3. Name: Travis Hottes Salway

- Highest academic degree(s): Master of Science (MSc)

- Affiliation: British Columbia Centres for Disease Control

4. Name: Paul Gustafson

- Highest academic degree(s): Doctor of Philosophy (PhD)

- Affiliation: The Department of Statistics, University of British Columbia

5. Name: Gina Ogilvie 
- Highest academic degree(s): Doctor of Medicine (MD); Doctor of Public Health (DrPH)

- Affiliation: British Columbia Centres for Disease Control

6. Name: Jean Shoveller

- Highest academic degree(s): Doctor of Philosophy (PhD)

- Affiliation: The School of Population and Public Health, University of British Columbia

\section{Name and address for correspondence}

Titilola Falasinnu, MHS

Address: 2206 East Mall, Vancouver, BC V6T 1Z3, Canada

Telephone number: 604.762.1908

Fax number: 604.822.4994

E-mail address: lola.falasinnu@ubc.ca

Key words: predictors, risk factors, risk assessment, chlamydia, gonorrhea, selective testing, screening recommendations, clinical guidelines

\section{Word count:}

3,461 


\title{
Predictors identifying those at increased risk for STDs: a theory-guided review of empirical literature and clinical guidelines
}

\begin{abstract}
Sexually transmitted diseases (STDs) are leading causes of substantial morbidity worldwide.

Identification of risk factors for estimating STD risk provides opportunities for optimizing service delivery in clinical settings, including improving case finding accuracy and increasing cost-efficiency by limiting the testing of low-risk individuals. The current study was undertaken to synthesize the evidence supporting commonly cited chlamydia and gonorrhea risk factors. The level of empirical support for the following predictors was strong/moderate: age, race/ethnicity, multiple lifetime sexual partners, sex with symptomatic partners, and concurrent STD diagnosis. The following predictors had weak evidence: socio-economic status, transactional sex, drug/alcohol use, condom use, and history of STD diagnosis. The most frequently listed predictors among nine clinical guidelines were younger age and multiple sexual partners; the least consistently listed predictor was inconsistent condom use. We found reasonably good concordance between risk factors consistently listed in the recommendations and predictors found to have strong empirical support in the literature. There is a need to continue building the evidence base to explicate the mechanisms and pathways of STD acquisition. We recommend periodic reviews of the level of support of predictors included in clinical guidelines to ensure that they are in accordance with empirical evidence.
\end{abstract}




\section{INTRODUCTION}

Sexually transmitted diseases (STDs) such as chlamydia and gonorrhea are leading causes of substantial morbidity worldwide; left untreated, they are often important exposures in the causal pathway for pelvic inflammatory disease, ectopic pregnancies, and infertility. In many countries, publicly funded sexual and reproductive health $(\mathrm{SRH})$ clinics are tasked with providing free or low cost STD testing and treatment services. However, the recent economic downturn, budgetary shortfalls, and cutbacks to public health infrastructure have resulted in SRH clinics operating at maximum capacity with limited resources. ${ }^{1,2}$ Concomitantly, there has been a shift towards the development of alternative models of service delivery in SRH clinics focused on patient-centered care and cost-effectiveness (e.g., internet-based STD testing; self-collected specimens), ${ }^{3,4}$ including providing "express visit" options to asymptomatic patients in SRH clinics who are deemed to be at low STD risk during which these patients do not undergo physical examination but are offered testing only. ${ }^{5,6}$ Because these alternative service delivery options involve patients having limited interactions with clinicians, another mechanism for recommending tests and triaging patients is required. There is, however, limited guidance in the literature about how to selectively test ${ }^{1}$ those at highest risk for STDs in the absence of clinician interaction.

Identification of risk factors predictive of STD risk provides the opportunity to deliver four key benefits in clinical settings: identifying specific patient groups with higher disease prevalence, identifying areas to target prevention services, improving case finding accuracy, and increasing costefficiency by limiting the testing of low-risk individuals. Plausible candidates for selective testing criteria include known determinants of prevalent infection (e.g., age, multiple partners). ${ }^{7}$ However, predictors used for selective testing are often derived from clinical guidelines that are broadly perceived as evidence-based statements; because they are developed by experts, they are assumed to

\footnotetext{
1 We use the phrase "selective testing" instead of "selective screening" because most studies in this review included individuals with STD signs and symptoms. By definition, only asymptomatic individuals are considered for screening purposes.
} 
have the same level of certainty and authority as conclusions generated by scientific methods. ${ }^{7,8}$ Few studies have been conducted to determine the degree to which evidence in the published literature supports the predictors included in recommendations. A better understanding of the use (or lack) of evidence in this area has the potential to inform the ways in which STD test recommendation practices unfold in the future.

The current study was undertaken to synthesize the evidence supporting predictors of chlamydia and gonorrhea (the two most common reportable STDs) in high-income jurisdictions in North America, Western Europe, and Australia - regions with comparable STD prevalence and social determinants of sexual health. The objectives are to identify risk factors cited as being most predictive of chlamydia and gonorrhea in clinical guidelines and in empirical studies. We also aimed to assess the strength of evidence supporting the association between these predictors and chlamydia and gonorrhea outcomes in empirical studies. Finally, we highlight discrepancies between predictors used in STD clinical guidelines and the relevant empirical evidence.

\section{METHODS}

\section{Literature search}

We identified the most recent and commonly cited clinical guidelines for screening chlamydia and gonorrhea issued by health organizations in high-income countries in North America and Europe, and Australia. We also identified empirical studies in journals readily accessible to SRH clinicians or experts in these settings and thus, limited our search to electronic searches of Englishlanguage studies published in OVID Medline, as well as manual searches of reference lists of papers identified. MeSH search terms included: 'screening'; and at least one of 'chlamydia', 'gonorrhea', 'STI', or 'STD'. Articles that measured demographical and behavioral predictors associated with STD diagnoses were included. Studies focusing on psychosocial factors (e.g., knowledge and attitudes, stress, self-esteem) were excluded, as these predictors are not consistently measured across 
studies. STD signs and symptoms were not examined as they are clearly indicative of infection. The search was limited to studies published 2003-2011, an era characterized by the expansion of highly sensitive tests (e.g., Nucleic Acid Amplification Tests) and urine-based testing, in an effort to ensure comparability in specimen collection and STD outcome assessment.

\section{Assessment of methodological quality}

Articles selected for inclusion were examined to assess their methodological quality. The following nine criteria ${ }^{9,10}$ were used to score the methodological quality of studies: study design, specimen collection, statistical methods, model selection, study sample description, variable definition, events per variable, outcome assessment, and study generalizability (see Table 1). Based on the scoring system, studies with a rating of 'unacceptable' ( $\leq 3$ points) were removed from further review. Studies rated as 'marginal' (4-5 points), 'acceptable' (6-7 points) and 'commendable' (8-9 points) were kept for empirical analysis stage of the review. The studies rated as 'commendable' or 'acceptable' were given greater weight when interpreting consistency or variable relationships.

\section{Data extraction}

To help clarify the relative strength or importance of each STD predictor, we categorized the predictors extracted from the empirical studies into two groups based on the proximatedeterminants framework ${ }^{11,12}:$ (1) proximate determinants, which are demographic, social or economic variables distally related to STDs, and (2) proximate determinants, which are directly associated with an individual's probability of exposure to STDs and the efficiency of STD transmission. Also, to determine whether the various factors identified in the included studies were significantly associated with STDs in multivariable analysis (if possible), a significance level of 0.05 was used. Because the studies included in this review were heterogeneous with respect to study design and predictor definition, pooling of data for meta-analyses was not possible. Therefore a qualitative data-synthesis was performed. ${ }^{13,14}$ 
Key predictors mentioned in multiple studies were retained to test the level of empirical support for their association with chlamydia or gonorrhea infection (STDs). The strengths of the evidence for predictors were assessed as follows ${ }^{13}$ : (1) Strong evidence: $>75 \%$ of multiple 'acceptable' or 'commendable' studies found consistent and statistically significant greater risk of infection; (2) Moderate evidence: $60 \%$ - 74\% of multiple 'acceptable' or 'commendable' studies found consistent and statistically significant greater risk of infection; (3) Inconclusive evidence: $45 \%-59 \%$ of multiple 'acceptable' or 'commendable' studies found consistent and statistically significant greater risk of infection; (4) Weak evidence: $<45 \%$ of 'acceptable' or 'commendable' studies found consistent and statistically significant greater risk of infection. In addition, predictors were also deemed to have insufficient evidence if few studies (i.e., less than the lowest quartile of the number of studies reviewed) examined the association between the predictor and infection.

\section{RESULTS}

\section{Overview of clinical guidelines}

We identified nine organizations issuing clinical guidelines in high-income contexts (Table 2). Six organizations listed clinical guidelines for women only, citing lack of evidence for the selective screening of men: the US Preventive Services Task Force (USPSTF) ${ }^{15,16}$, the American Academy of Family Practice (AAFP) ${ }^{15,16}$, the US Centers for Disease Control and Prevention (USCDC) ${ }^{17}$, the American College of Obstetrics and Gynecology (ACOG) ${ }^{18}$, the Public Health Agency of Canada $(\text { PHAC) })^{19}$, and the Society of Obstetricians and Gynecologists (SOGC) ${ }^{20}$ (Table 2). Three other organizations reported clinical guidelines for males and females combined. ${ }^{21-23}$

Almost all the organizations support the universal screening of young sexually active individuals for chlamydia and to some extent gonorrhea (Table 2). Occasionally, clinical guidelines differ across organizations, mainly because of distinctions in mission and target audience ${ }^{24}$ as well as the epidemiology of the various STDs. For example, the USCDC and PHAC focus on population 
health in the US and Canada, respectively, while other organizations focus on the clinical settings. ${ }^{24}$ A closer examination of predictors revealed incongruities between the organizations, even among those in the same country (Table 2). For example, clinical recommendations issued by both the PHAC and the SOGC agree on screening individuals with the following risk factors for chlamydia or gonorrhea infection: younger age, sexual contact of STD case, previous STD diagnosis, new sexual partners, multiple sexual partners, use of drugs or alcohol during sex, sex in exchange for money or gifts, and individuals or travelers from endemic regions (Table 2). However, the PHAC also identifies the following risk factors: street involvement (or homelessness) and sexual contacts of people with any of the aforementioned risk factors (Table 2).

The most consistently listed predictors among clinical recommendations were younger age and multiple sexual partners as all nine organizations recommended screening individuals with these two risk factors (Table 2). Approximately $90 \%$ of the nine organizations recommended screening individuals who are sexual contacts of STD cases and also those who use alcohol or drugs during sexual relations. The least consistently listed predictors were street involvement $(11 \%)$, inconsistent condom use (44\%), and individuals or travelers from STD endemic regions (56\%).

\section{Assessment of included studies}

Based on the article selection process listed in Figure 1, 75 studies were rated, most of which included a mix of symptomatic and asymptomatic individuals (Table 3). Approximately 68\% of studies examined chlamydia infection only, $8 \%$ examined gonorrhea outcomes only, and 19\% examined both outcomes (Table 3). Approximately 32\% of the studies had female only populations and 20\% included male only populations. Nearly 50\% were from the United States (Table 3). Some studies used population-based participant recruitment (21\%); most studies were cross-sectional in design (87\%). A minority of the studies examined only asymptomatic populations (8\%). Based on the nine criteria of methodological quality, a total of 5 studies $(7 \%)$ received a score of $\leq 3 / 9$ and 
thus were rated as 'unacceptable'. ${ }^{25-29}$ These studies were omitted from the second stage of review. Studies rated as 'marginal' $(24 \%)^{7,30-46}$, 'acceptable' $(41 \%)^{47-77}$, and 'commendable' $(28 \%)^{4,78-97}$ were retained in the review. Table 4 summarizes the 70 studies that were retained for further assessment.

Empirical support for the following seven variables was strong or moderately strong: age (at time of study), race/ethnicity, multiple lifetime sexual partners, multiple sexual partners in recent months, sex with infected partners, sex with symptomatic partners, and concurrent STD diagnosis. Three predictors had inconclusive evidence: age at sexual debut, sex with causal partners, and sex with new partners. Eight predictors had weak evidence associating them with STD diagnosis: socioeconomic status, marital status, sexual partners from overseas, sex in exchange for gifts/money, drug/alcohol use, condom use, sex with regular partners, and history of STD diagnosis.

Predictors examined by eleven studies or less (i.e., less than the lowest quartile of the number of studies reviewed) were deemed to have insufficient research. There were insufficient empirical studies to determine the nature of the association between the following six variables and infection: sex in exchange for gifts/money, sexual partners from overseas, sex with regular partners, sex with casual partners, concurrent STD diagnosis, and sex with symptomatic partners. Six variables were not included in any clinical guidelines: race/ethnicity, socio-economic status, marital status, sex with regular partners, sex with casual partners, and sex with symptomatic partner. Assessment of the predictive abilities of underlying determinants

The following underlying determinants of STD diagnosis were identified in this review: age (at study time), age at sexual debut, race/ethnicity, socio-economic status (SES), sex work, marital status, and drug/alcohol use (Table 4). Younger age was consistently associated with increased risk of STD acquisition (especially chlamydia infection); 85\% of 'commendable' studies reported a significant association between age and STD diagnosis in their multivariable analyses (Table 4). There was inconclusive evidence in the current review associating early age at sexual debut to STD 
diagnosis; only $25 \%$ of 'commendable' studies and $56 \%$ of 'acceptable' studies that examined this risk factor found a significant relationship between age at sexual debut and STD diagnosis (Table 4). The level of empirical evidence in the current review for the association between race/ethnicity and STD diagnosis was moderate $-72 \%$ of 'commendable' studies and $68 \%$ of 'acceptable' studies measuring this association found significant associations in their multivariable analyses (Table 4). Most of these studies found a higher risk of infection among ethnic minority individuals in multivariate analysis. ${ }^{4,86}$ Conversely, the level of empirical evidence of the association between SES and STD diagnosis was rated as weak - only $56 \%$ of 'commendable' studies and $18 \%$ 'acceptable' studies found a significant relationship (Table 4). SES was not associated with infection in multivariable analyses using any measure, including educational level ${ }^{66,87,94}$ and employment status. 48,57

This review found weak evidence for the association between STD diagnosis and the following predictors: drug/alcohol use and sex in exchange for drugs/money (Table 4). Only 33\% of 'commendable' studies and 33\% of 'acceptable' studies found associations between drug/alcohol use and STD diagnosis.

Assessment of the predictive abilities of determinants of exposure of susceptible to infected people

The following proximate determinants of exposure to infected people were identified in this review: multiple lifetime sexual partners, multiple sex partners in recent months, sexual partners from overseas, sex with regular partners, sex with casual partners, sex with new partners, sex with infected partners, and sex with symptomatic partners (Table 4). The empirical evidence linking multiple lifetime sexual partners (i.e., more than 1 sexual partner) and STDs was strong. However, there was no consistent evidence for the association with higher cut-points (e.g., $>2,>5$, or $>10$ partners). All of the 'commendable' studies and 57\% of 'acceptable' studies showed significant associations between multiple lifetime sexual partners and STD diagnosis (Table 4). We also found 
strong evidence for the association between having multiple sexual partners in recent months and STD diagnosis. Approximately 64\% of 'commendable' studies and 57\% of 'acceptable' studies that measured this relationship found a significant association between having multiple sexual partners in recent months in multivariable analysis (Table 4).

This review also explored the association between STD diagnosis and sexual partner characteristics. The evidence for the association between STD diagnosis and the following predictors was either inconclusive, weak and/or explored in few studies: sex with regular partners, sex with casual partners, and sex with partners from overseas (Table 4). We found inconclusive evidence regarding the association between having a new partner and STD diagnosis (only about $60 \%$ of 'commendable' studies and $33 \%$ of 'acceptable' studies that measured this variable found significant associations with STD diagnosis). This review found strong evidence between STD diagnosis and sex with infected partners or symptomatic partners. All of the 'commendable' studies and $75 \%$ of 'acceptable' studies measuring this association between found a significant association. Assessment of the predictive abilities of determinants of the efficiency of transmission

The following proximate determinants of the efficiency of infection transmission were identified: history of STD diagnosis, concurrent STD diagnosis, and condom use (Table 4). We found weak evidence for the association between having a history of STD diagnosis and infection. Only $33 \%$ of 'commendable' studies and $45 \%$ of 22 'acceptable' studies that measured this association found a significant relationship between history of STD diagnosis and STD diagnosis in multivariable analyses. There was, however, strong evidence for the association between having a concurrent STD diagnosis and infection. Both of the 2 'commendable' studies and $75 \%$ of the 4 'acceptable' studies that explored the relationship between having a concurrent STD diagnosis and infection found a significant association, although few studies explored this relationship $(\mathrm{n}=11)$. 
The empirical evidence for the association between the use of condoms and infection was weak across the studies. Only 36\% of 'commendable' studies, $26 \%$ of 'acceptable' studies and 25\% of 'marginal' studies found significant associations between condom use and STD diagnosis. There were no notable trends among the studies examining the relationship between condom use and STD diagnosis, although self-report condom use is an enduring measurement problem in this field. ${ }^{98}$

\section{Discussion}

The increasing availability and use of noninvasive diagnostic tests for STD diagnosis has reopened discussions about the feasibility of scaling up selective testing efforts to include the general population. Thus, a better understanding of the availability (or lack) of evidence in this area may help inform the ways in which existing selective testing criteria continue to be implemented as well as the potential for novel approaches to STD testing intervention practices to unfold in the future, including internet-based testing initiatives. ${ }^{99}$ This review was conceptualized as a guide to help decision makers considering undertaking selective testing programs in alternative settings such as the internet; specifically, the findings may help them augment selective testing by identifying variables to include in risk assessment questionnaires.

This review accomplishes two tasks. First, it summarizes the literature on the most consistent predictors of chlamydia and gonorrhea infection, which were identified after a wide range of patient characteristics was assessed. Age, number of sexual partners, sex with a symptomatic partner, sex with an infected partner and concurrent STD diagnosis are perhaps the most intuitive predictors of STD risk. The current review has reinforced the importance of these variables. Second, this review adopted a theoretical framework to contextualize the findings. The proximatedeterminants framework hypothesizes that that after adjustment for the proximate determinants or socio-behavioral predictors, relationships between the underlying or socio-demographic characteristics and STD diagnosis should be non-significant. ${ }^{11,12}$ In this review, several underlying 
predictors (e.g., age and race/ethnicity) were found to be significantly associated with STD diagnosis even in studies that adjusted for proximate determinants. This finding suggests that some proximate determinants may potentially be measured with error. ${ }^{11,12}$ It also highlights the complexity inherent in the self-reported nature of proximate determinants such as condom use, coupled with measurement issues in underlying predictors (e.g., race/ethnicity). ${ }^{101}$

We found reasonably good concordance between risk factors consistently listed in the recommendations (e.g., younger age, multiple sexual partners, and sexual contact of STD case) and predictors found to have strong empirical support in the literature (i.e., if a risk factor is included in more guidelines, then there is more evidence supporting its predictive capacity). However, when the guidelines are considered individually or in isolation, there are large inconsistencies between the STD risk factors cited by the organizations that may reflect the lack of clarity, transparency, and consensus about how high risk behaviors influence specific STD diagnosis. Another possible explanation for the differences in recommendations may be due to regional differences in prevalence. These inconsistencies could also reflect the overall priorities of organizations issuing recommendation statements (e.g., minimizing harm from screening and cost-effectiveness versus concerns about missed cases).

This review has some limitations. There was a paucity of empirical studies examining the strength of predictors in asymptomatic populations. Because most STDs are asymptomatic, it is important to elucidate the predictive ability of risk factors in the absence of symptoms. However, most studies combined symptomatic and asymptomatic individuals in multivariable analyses likely masking important differences between these populations. We were unable to identify clear trends in associations between predictors and STDs among the six studies that explicitly examined asymptomatic populations. This limitation may have considerable impact on some findings. First, it is likely that the effect sizes of other predictors were underestimated in multivariable regression 
models that included symptoms as covariates because of the strong association between symptoms and STDs. Second, the significant associations between some predictors and STDs may be a function of selection bias in SRH clinics settings because of differential health seeking behaviors. ${ }^{102,103}$ It is hypothesized that when health-seeking behavior of certain population sub-groups (e.g., older adults, racial/ethnic minorities) is low, its percentage of symptomatic clinic visits will be high because these individuals are less likely to visit SRH clinics for routine screening. ${ }^{102,103}$ Thus, the associations found may not actually reflect a higher concentration of risk in certain sub-groups but is a reflection of the over-representation of these sub-groups in symptomatic populations presenting to clinics. Further studies assessing asymptomatic populations are, thus, warranted.

Also, we were unable to synthesize the evidence for predictors of chlamydia and gonorrhea separately as there were few studies examining gonorrhea outcomes only. Based on a sub-analysis, the most important predictors of gonorrhea outcomes only were no different from those for chlamydia outcomes only, despite the differences in the epidemiology and social determinants between these two infections. In addition, we were unable to evaluate the extent of co-linearity between predictors. However, a closer examination of model building in the individual articles revealed that most studies handled co-linearity appropriately, e.g., including one of the co-linear variables in the final model. We were unable to synthesize the evidence separately for special populations (e.g., men who have sex with men, men who have sex with women) as clinical guidelines and empirical analyses for these groups were inconsistently reported.

We would like to draw some attention to some differences in guideline recommendations for population based screening at general practitioner settings, for example compared to SRH clinics. The identification of high-risk individuals in these two settings requires slightly differently approaches to decision making. For example, in order to reduce STD incidence on a population level, studies of disease dynamics recommend focusing screening efforts on core groups who are 
more likely to have highest concentration of risk behaviors and infection incidence (e.g., adolescents, sex workers). ${ }^{107-109}$ However, in STD clinic settings, where individual-level screening decision making is priority, the development of personalized risk scoring tool may have more relevance. ${ }^{61,110}$ In the future, SRH clinicians may develop risk estimation or prediction tools by combining the risk factors identified in this review. The prediction tools may have important implications for targeted risk communication and STD testing motivation among patients attending sexual and reproductive health clinics. ${ }^{100}$ Finally, we recommend that periodic reviews of the evolving evidence base in this substantive area have good potential to contribute to the planning and evaluation of selective testing intervention practices as they unfold in the future. There is, however, a need to continue to build the evidence base, particularly for special populations, and as STD testing intervention practices expand to non-traditional settings (e.g., the internet; the home).

\section{Funding acknowledgement}

This work was supported by the Canadian Institutes of Health Research Doctoral Research Award. 


\section{REFERENCES}

1. Golden MR, Kerndt PR. Improving Clinical Operations: Can we and should we Save our STD Clinics? Sex.Transm.Dis. 2010;37:264-5.

2. Rietmeijer CA, Mettenbrink C. Why we should Save our STD Clinics. Sex.Transm.Dis. 2010;37:591.

3. Richardus JH, Gotz HM. Risk Selection and Targeted Interventions in Community-Based Control of Chlamydia. Curr.Opin.Infect.Dis. 2007;20:60-5.

4. Gotz HM, van Bergen JE, Veldhuijzen IK, et al. A Prediction Rule for Selective Screening of Chlamydia Trachomatis Infection. Sex.Transm.Infect. 2005;81:24-30.

5. Fairley CK, Vodstrcil LA, Read T. The Importance of Striving for Greater Efficiency. Sex. Health. 2011;8:3-4.

6. Shamos SJ, Mettenbrink CJ, Subiadur JA, Mitchell BL, Rietmeijer CA. Evaluation of a TestingOnly "Express" Visit Option to Enhance Efficiency in a Busy STI Clinic. Sex.Transm.Dis. 2008;35:336-40.

7. Manhart LE, Marrazzo JM, Fine DN, Kerani RP, Golden MR. Selective Testing Criteria for Gonorrhea among Young Women Screened for Chlamydial Infection: Contribution of Race and Geographic Prevalence. J.Infect.Dis. 2007;196:731-7.

8. Sniderman AD, Furberg CD. Why Guideline-Making Requires Reform. JAMA 2009;301:429-31.

9. Ownsworth T, McKenna K. Investigation of Factors Related to Employment Outcome Following Traumatic Brain Injury: A Critical Review and Conceptual Model. Disabil.Rehabil. 2004;26:765-83.

10. Turner BJ, Fleming JM, Ownsworth TL, Cornwell PL. The Transition from Hospital to Home for Individuals with Acquired Brain Injury: A Literature Review and Research Recommendations.

Disabil.Rebabil. 2008;30:1153-76.

11. Boerma JT, Weir SS. Integrating Demographic and Epidemiological Approaches to Research on HIV/AIDS: The Proximate-Determinants Framework. J.Infect.Dis. 2005;191 Suppl 1:S61-7.

12. Lewis JJ, Donnelly CA, Mare P, Mupambireyi Z, Garnett GP, Gregson S. Evaluating the Proximate Determinants Framework for HIV Infection in Rural Zimbabwe. Sex.Transm.Infect. 2007;83 Suppl 1:i61-69.

13. de Rooij A, Roorda LD, Otten RH, van der Leeden M, Dekker J, Steultjens MP. Predictors of Multidisciplinary Treatment Outcome in Fibromyalgia:A Systematic Review. Disabil.Rehabil. 2013;35:437-49.

14. Ariens GA, van Mechelen W, Bongers PM, Bouter LM, van der Wal G. Psychosocial Risk Factors for Neck Pain: A Systematic Review. Am.J.Ind.Med. 2001;39:180-93.

15. U.S. Preventive Services Task Force. Screening for Gonorrhea. http://www.uspreventiveservicestaskforce.org/uspstf/uspsgono.htm (last accessed 07/22 2013). 16. U.S. Preventive Services Task Force. Screening for Chlamydial Infection: U.S. Preventive Services Task Force Recommendation Statement. Ann.Intern.Med. 2007;147:128-34. 17. Workowski KA, Berman S, Centers for Disease Control and Prevention (CDC). Sexually Transmitted Diseases Treatment Guidelines, 2010. MMWR Recomm Rep. 2010;59:1-110. 18. American Congress of Obstetricians and Gynecologists. Annual Women's Healthcare: High-risk factors.

http://www.acog.org/About ACOG/ACOG Departments/Annual Womens Health Care/High -Risk Factors (last accessed 07/22 2013). 19. Public Health Agency of Canada. Canadian Guidelines on Sexually Transmitted Infections

- Updated January 2010. http://www.phac-aspc.gc.ca/std-mts/sti-its/cgsti-ldcits/index-eng.php (last accessed 07/22 2013). 
20. The Society of Obstetricians and Gynaecologists of Canada. Screening recommendations for asymptomatic individuals. http://www.sexualityandu.ca/health-care-professionals/sexuallytransmitted-infections/screening-recommendations-for-asymptomatic-individuals (last accessed 07/22 2013).

21. British Association for Sexual Health and HIV. Sexually Transmitted Infections: UK National Screening and Testing Guidelines. http://www.bashh.org/documents/59/59.pdf (last accessed 07/22 2013).

22. Australasian Society for HIV Medicine. Guidelines for Managing Sexually Transmitted

Infections: Screening of Asymptomatic Men and Women.

http:// silverbook.health.wa.gov.au/Default.asp?PublicationID=1\&SectionID=236 (last accessed 07/22 2013).

23. Radcliffe KW, European Branch of the International Union against Sexually Transmitted Infection and the European Office of the World Health Organization. Introduction. European STD Guidelines. Int.J.STD AIDS 2001;12 Suppl 3:2-3.

24. Meyers D, Wolff T, Gregory K, et al. USPSTF Recommendations for STI Screening. Am.Fam.Physician 2008;77:819-24.

25. Kong FY, Hocking JS, Link CK, Chen MY, Hellard ME. Sex and Sport: Chlamydia Screening in Rural Sporting Clubs. BMC Infect.Dis. 2009;9:73.

26. Greene JP, Stafford E. Prevalence of Chlamydia Trachomatis among Active Duty Male Soldiers Reporting to a Troop Medical Clinic for Routine Health Care. South.Med.J. 2007;100:478-81.

27. Mak RP, Van Renterghem L, Traen A. Chlamydia Trachomatis in Female Sex Workers in Belgium: 1998-2003. Sex.Transm.Infect. 2005;81:89-90.

28. Menon-Johansson AS, Winston A, Matthews G, Portsmouth S, Daniels D. The First Point Prevalence Study of Genital Chlamydia Trachomatis Infection in Young Male Inmates in the UK. Int.J.STD AIDS 2005;16:799-801.

29. Powell J, O'Connor C, O'hlarlaithe M, Saunders J, De Freitas J. Chlamydia Trachomatis

Prevalence in Men in the Mid-West of Ireland. Sex.Transm.Infect. 2004;80:349-53.

30. Annan NT, Sullivan AK, Nori A, et al. Rectal Chlamydia--a Reservoir of Undiagnosed Infection in Men Who have Sex with Men. Sex.Transm.Infect. 2009;85:176-9.

31. Dicker LW, Mosure DJ, Kay RS, Shelby L, Cheek JE, Region VIII Infertility Prevention P. An Ongoing Burden: Chlamydial Infections among Young American Indian Women. Matern.Child Health J. 2008;12:25-9.

32. Hince D, Brett T, Mak D, Bulsara M, Moorhead R, Arnold-Reed D. Opportunistic Screening for Chlamydia in Young Men. Aust.Fam.Physician 2009;38:734-7.

33. Spasovski MS, Simjanovska LJ, Taleski V, et al. Screening of Chlamydia Trachomatis Urogenital Infections among the Male and Female Population of the Republic of Macedonia.

J.Eur.Acad.Dermatol.Venereol. 2005;19:427-30.

34. Simms I, Talebi A, Rhia J, et al. The English National Chlamydia Screening Programme:

Variations in Positivity in 2007/2008. Sex.Transm.Dis. 2009;36:522-7.

35. Hocking J, Fairley CK. Do the Characteristics of Sexual Health Centre Clients Predict Chlamydia Infection Sufficiently Strongly to Allow Selective Screening? Sex.Health. 2005;2:185-92.

36. Tipple C, Hill SC, Smith A. Is Screening for Pharyngeal Chlamydia Trachomatis Warranted in High-Risk Groups?. Int.J.STD AIDS 2010;21:770-1.

37. Mossong J, Muller M, Majery N, Mardaga C, Decruyenaere F, Schneider F. Screening for Chlamydia Trachomatis in Secondary Schools, Family Planning and Occupational Health Centres in Luxembourg. Sex.Transm.Infect. 2009;85:455-8.

38. Paukku M, Kilpikari R, Puolakkainen M, Oksanen H, Apter D, Paavonen J. Criteria for Selective Screening for Chlamydia Trachomatis. Sex.Transm.Dis. 2003;30:120-3. 
39. Ivens D, Macdonald K, Bansi L, Nori A. Screening for Rectal Chlamydia Infection in a Genitourinary Medicine Clinic. Int.J.STD AIDS 2007;18:404-6.

40. Landes M, Thorne C, Barlow P, et al. Prevalence of Sexually Transmitted Infections in HIV-1 Infected Pregnant Women in Europe. Eur.J.Epidemiol. 2007;22:925-36.

41. Barry PM, Kent CK, Klausner JD. Risk Factors for Gonorrhea among Heterosexuals--San Francisco, 2006. Sex.Transm.Dis. 2009;36:S62-6.

42. Hirst H, Dinsmore WW. Chlamydia Screening Programme, HMP Hydebank Wood Young Offender Centre, Belfast, Northern Ireland, UK. Int.J.STD AIDS 2009;20:360-1.

43. Schillinger JA, Dunne EF, Chapin JB, et al. Prevalence of Chlamydia Trachomatis Infection among Men Screened in 4 U.S. Cities. Sex.Transm.Dis. 2005;32:74-7.

44. Matteelli A, Beltrame A, Carvalho AC, et al. Chlamydia Trachomatis Genital Infection in Migrant Female Sex Workers in Italy. Int.J.STD AIDS 2003;14:591-5.

45. Steenbeek A, Tyndall M, Sheps S, Rothenberg R. An Epidemiological Survey of Chlamydial and Gonococcal Infections in a Canadian Arctic Community. Sex.Transm.Dis. 2009;36:79-83.

46. Geisler WM, James AB. Chlamydial and Gonococcal Infections in Women Seeking Pregnancy Testing at Family-Planning Clinics. Am.J.Obstet.Gynecol. 2008;198:502.e1,502.e4.

47. Bakken IJ, Nordbo SA, Skjeldestad FE. Chlamydia Trachomatis Testing Patterns and Prevalence of Genital Chlamydial Infection among Young Men and Women in Central Norway 1990-2003: A Population-Based Registry Study. Sex.Transm.Dis. 2006;33:26-30.

48. Bozicevic I, Grgic I, Zidovec-Lepej S, et al. Urine-Based Testing for Chlamydia Trachomatis among Young Adults in a Population-Based Survey in Croatia: Feasibility and Prevalence. BMC Public Health 2011;11:230.

49. Gaydos CA, Kent CK, Rietmeijer CA, et al. Prevalence of Neisseria Gonorrhoeae among Men Screened for Chlamydia Trachomatis in Four United States Cities, 1999-2003. Sex.Transm.Dis. 2006;33:314-9.

50. Jackson Y, Sebo P, Aeby G, et al. Prevalence and Associated Factors for Chlamydia Trachomatis Infection among Undocumented Immigrants in a Primary Care Facility in Geneva, Switzerland: A Cross-Sectional Study. J.Immigr Minor.Health. 2010;12:909-14.

51. Joesoef MR, Mosure DJ. Prevalence of Chlamydia in Young Men in the United States from Newly Implemented Universal Screening in a National Job Training Program. Sex.Transm.Dis. 2006;33:636-9.

52. Richardson E, Sellors JW, Mackinnon S, et al. Prevalence of Chlamydia Trachomatis Infections and Specimen Collection Preference among Women, using Self-Collected Vaginal Swabs in Community Settings. Sex.Transm.Dis. 2003;30:880-5.

53. Singh D, Fine DN, Marrazzo JM. Chlamydia Trachomatis Infection among Women Reporting Sexual Activity with Women Screened in Family Planning Clinics in the Pacific Northwest, 1997 to 2005. Am.J.Public Health 2011;101:1284-90.

54. Steiner AS, Haller DM, Elger BS, Sebo P, Gaspoz JM, Wolff H. Chlamydia Trachomatis Infection in a Swiss Prison: A Cross Sectional Study. Swiss Med.Wkly. 2010;140:w13126.

55. Sutton TL, Martinko T, Hale S, Fairchok MP. Prevalence and High Rate of Asymptomatic Infection of Chlamydia Trachomatis in Male College Reserve Officer Training Corps Cadets. Sex.Transm.Dis. 2003;30:901-4.

56. Uuskula A, Kals M, Denks K, et al. The Prevalence of Chlamydial Infection in Estonia: A Population-Based Survey. Int.J.STD AIDS 2008;19:455-8.

57. Stein CR, Kaufman JS, Ford CA, Leone PA, Feldblum PJ, Miller WC. Screening Young Adults for Prevalent Chlamydial Infection in Community Settings. Ann.Epidemiol. 2008;18:560-71. 
58. Andersen B, van Valkengoed I, Olesen F, Moller JK, Ostergaard L. Value of Self-Reportable Screening Criteria to Identify Asymptomatic Individuals in the General Population for Urogential Chlamydia Trachomatis Infection Screening. Clin.Infect.Dis. 2003;36:837-44.

59. Bernstein KT, Chow JM, Ruiz J, et al. Chlamydia Trachomatis and Neisseria Gonorrhoeae Infections among Men and Women Entering California Prisons. Am.J.Public Health 2006;96:1862-6. 60. Goulet V, de Barbeyrac B, Raherison S, et al. Prevalence of Chlamydia Trachomatis: Results from the First National Population-Based Survey in France. Sex.Transm.Infect. 2010;86:263-70. 61. Wand H, Guy R, Donovan B, McNulty A. Developing and Validating a Risk Scoring Tool for Chlamydia Infection among Sexual Health Clinic Attendees in Australia: A Simple Algorithm to Identify those at High Risk of Chlamydia Infection. BMJ Open 2011;1:e000005.

62. Belenko S, Dembo R, Weiland D, et al. Recently Arrested Adolescents are at High Risk for Sexually Transmitted Diseases. Sex.Transm.Dis. 2008;35:758-63.

63. Asbel LE, Newbern EC, Salmon M, Spain CV, Goldberg M. School-Based Screening for Chlamydia Trachomatis and Neisseria Gonorrhoeae among Philadelphia Public High School Students. Sex.Transm.Dis. 2006;33:614-20.

64. Robertson AA, Thomas CB, St Lawrence JS, Pack R. Predictors of Infection with Chlamydia Or Gonorrhea in Incarcerated Adolescents. Sex.Transm.Dis. 2005;32:115-22.

65. Kahn RH, Moseley KE, Thilges JN, Johnson G, Farley TA. Community-Based Screening and Treatment for STDs: Results from a Mobile Clinic Initiative. Sex.Transm.Dis. 2003;30:654-8. 66. Doherty IA, Adimora AA, Schoenbach VJ, Aral SO. Correlates of Gonorrhoea among African Americans in North Carolina. Int.J.STD AIDS 2007;18:114-7.

67. McDonagh P, Ryder N, McNulty AM, Freedman E. Neisseria Gonorrhoeae Infection in Urban Sydney Women: Prevalence and Predictors. Sex.Health. 2009;6:241-4.

68. Rao GG, Bacon L, Evans J, et al. Prevalence of Neisseria Gonorrhoeae Infection in Young Subjects Attending Community Clinics in South London. Sex.Transm.Infect. 2008;84:117-21. 69. Bozicevic I, Fenton KA, Martin IM, et al. Epidemiological Correlates of Asymptomatic Gonorrhea. Sex.Transm.Dis. 2006;33:289-95.

70. Geisler WM, Chow JM, Schachter J, McCormack WM. Pelvic Examination Findings and Chlamydia Trachomatis Infection in Asymptomatic Young Women Screened with a Nucleic Acid Amplification Test. Sex.Transm.Dis. 2007;34:335-8.

71. Gorgos L, Fine D, Marrazzo J. Chlamydia Positivity in American Indian/Alaska Native Women Screened in Family Planning Clinics, 1997-2004. Sex.Transm.Dis. 2008;35:753-7.

72. LaMontagne DS, Fenton KA, Randall S, Anderson S, Carter P. Establishing the National Chlamydia Screening Programme in England: Results from the First Full Year of Screening. Sex.Transm.Infect. 2004;80:335-41.

73. Lofy KH, Hofmann J, Mosure DJ, Fine DN, Marrazzo JM. Chlamydial Infections among Female Adolescents Screened in Juvenile Detention Centers in Washington State, 1998-2002. Sex.Transm.Dis. 2006;33:63-7.

74. Satterwhite CL, Tian LH, Braxton J, Weinstock H. Chlamydia Prevalence among Women and Men Entering the National Job Training Program: United States, 2003-2007. Sex.Transm.Dis. 2010;37:63-7.

75. Arcari CM, Gaydos JC, Howell MR, McKee KT, Gaydos CA. Feasibility and Short-Term Impact of Linked Education and Urine Screening Interventions for Chlamydia and Gonorrhea in Male Army Recruits. Sex.Transm.Dis. 2004;31:443-7.

76. Trick WE, Kee R, Murphy-Swallow D, Mansour M, Mennella C, Raba JM. Detection of Chlamydial and Gonococcal Urethral Infection during Jail Intake: Development of a Screening Algorithm. Sex.Transm.Dis. 2006;33:599-603. 
77. Javanbakht M, Murphy R, Harawa NT, et al. Sexually Transmitted Infections and HIV Prevalence among Incarcerated Men Who have Sex with Men, 2000-2005. Sex.Transm.Dis. 2009;36:S17-21.

78. Gaydos CA, Howell MR, Quinn TC, McKee KT,Jr, Gaydos JC. Sustained High Prevalence of Chlamydia Trachomatis Infections in Female Army Recruits. Sex.Transm.Dis. 2003;30:539-44.

79. Geisler WM, Chyu L, Kusunoki Y, Upchurch DM, Hook EW,3rd. Health Insurance Coverage, Health Care-Seeking Behaviors, and Genital Chlamydial Infection Prevalence in Sexually Active Young Adults. Sex.Transm.Dis. 2006;33:389-96.

80. Joffe A, Rietmeijer CA, Chung SE, et al. Screening Asymptomatic Adolescent Men for Chlamydia Trachomatis in School-Based Health Centers using Urine-Based Nucleic Acid Amplification Tests. Sex.Transm.Dis. 2008;35:S19-23.

81. McDonnell DD, Levy V, Morton TJ. Risk Factors for Chlamydia among Young Women in a Northern California Juvenile Detention Facility: Implications for Community Intervention. Sex.Transm.Dis. 2009;36:S29-33.

82. Scott Lamontagne D, Baster K, Emmett L, et al. Incidence and Reinfection Rates of Genital Chlamydial Infection among Women Aged 16-24 Years Attending General Practice, Family Planning and Genitourinary Medicine Clinics in England: A Prospective Cohort Study by the Chlamydia Recall Study Advisory Group. Sex.Transm.Infect. 2007;83:292-303.

83. Skjeldestad FE, Marsico MA, Sings HL, Nordbo SA, Storvold G. Incidence and Risk Factors for Genital Chlamydia Trachomatis Infection: A 4-Year Prospective Cohort Study. Sex.Transm.Dis. 2009;36:273-9.

84. van Bergen J, Gotz HM, Richardus JH, et al. Prevalence of Urogenital Chlamydia Trachomatis Increases significantly with Level of Urbanisation and Suggests Targeted Screening Approaches: Results from the First National Population Based Study in the Netherlands. Sex.Transm.Infect. 2005;81:17-23.

85. Gotz HM, Veldhuijzen IK, Habbema JD, Boeke AJ, Richardus JH, Steyerberg EW. Prediction of Chlamydia Trachomatis Infection: Application of a Scoring Rule to Other Populations.

Sex.Transm.Dis. 2006;33:374-80.

86. La Montagne DS, Patrick LE, Fine DN, Marrazzo JM, Region X Infertility Prevention Project.

Re-Evaluating Selective Screening Criteria for Chlamydial Infection among Women in the U S Pacific Northwest. Sex.Transm.Dis. 2004;31:283-9.

87. Latino MA, Caneparo A, Rosso C, et al. Prevalence and Risk Factors for Chlamydia Trachomatis Infection in Young Women in North-West of Italy. Minerva Ginecol. 2008;60:29-37.

88. Salfa MC, Latino MA, Regine V, et al. Prevalence and Determinants of Chlamydia Trachomatis Infection among Sexually Active Women in Turin, Italy. ITALIAN JOURNAL OF PUBLIC HEALTH 2011;8:295-301.

89. Berry SA, Ghanem KG, Page KR, et al. Increased Gonorrhoea and Chlamydia Testing did Not Increase Case Detection in an HIV Clinical Cohort 1999-2007. Sex.Transm.Infect. 2011;87:469-75. 90. Datta SD, Sternberg M, Johnson RE, et al. Gonorrhea and Chlamydia in the United States among Persons 14 to 39 Years of Age, 1999 to 2002. Ann.Intern.Med. 2007;147:89-96.

91. Einwalter LA, Ritchie JM, Ault KA, Smith EM. Gonorrhea and Chlamydia Infection among Women Visiting Family Planning Clinics: Racial Variation in Prevalence and Predictors.

Perspect.Sex.Reprod.Health. 2005;37:135-40.

92. Hardick J, Hsieh YH, Tulloch S, Kus J, Tawes J, Gaydos CA. Surveillance of Chlamydia

Trachomatis and Neisseria Gonorrhoeae Infections in Women in Detention in Baltimore, Maryland. Sex.Transm.Dis. 2003;30:64-70. 
93. Jin F, Prestage GP, Mao L, et al. Incidence and Risk Factors for Urethral and Anal Gonorrhoea and Chlamydia in a Cohort of HIV-Negative Homosexual Men: The Health in Men Study. Sex.Transm.Infect. 2007;83:113-9.

94. Al-Tayyib AA, Miller WC, Rogers SM, et al. Evaluation of Risk Score Algorithms for Detection of Chlamydial and Gonococcal Infections in an Emergency Department Setting. Acad.Emerg.Med. 2008;15:126-35.

95. Merchant RC, DePalo DM, Liu T, Rich JD, Stein MD. Developing a System to Predict Laboratory-Confirmed Chlamydial and/Or Gonococcal Urethritis in Adult Male Emergency Department Patients. Postgrad.Med. 2010;122:52-60.

96. Mehta SD, Hall J, Lyss SB, Skolnik PR, Pealer LN, Kharasch S. Adult and Pediatric Emergency Department Sexually Transmitted Disease and HIV Screening: Programmatic Overview and Outcomes. Acad.Emerg.Med. 2007;14:250-8.

97. Chen MY, Rohrsheim R, Donovan B. Chlamydia Trachomatis Infection in Sydney Women. Aust.N.Z.J.Obstet.Gynaecol. 2005;45:410-3.

98. Vanable PA, Carey MP, Brown JL, et al. Test-Retest Reliability of Self-Reported HIV/STDRelated Measures among African-American Adolescents in Four U.S. Cities. J.Adolesc.Health 2009;44:214-21.

99. Shoveller J, Knight R, Davis W, Gilbert M, Ogilvie G. Online Sexual Health Services: Examining Youth's Perspectives. Can.J.Public Health 2012;103:14-8.

100. Falasinnu T, Gustafson P, Gilbert M, Shoveller J. Risk Prediction in Sexual Health Contexts: Protocol. JMIR Res.Protoc. 2013;2:e57.

101. Adimora AA, Schoenbach VJ, Martinson FE, Donaldson KH, Fullilove RE, Aral SO. Social Context of Sexual Relationships among Rural African Americans. Sex.Transm.Dis. 2001;28:69-76. 102. Guan J, Wu Z, Li L, et al. Self-Reported Sexually Transmitted Disease Symptoms and Treatment-Seeking Behaviors in China. AIDS Patient Care STDS 2009;23:443-8. 103. Matser A, Luu N, Geskus R, et al. Higher Chlamydia Trachomatis Prevalence in Ethnic Minorities does Not always Reflect Higher Sexual Risk Behaviour. PLoS One 2013;8:e67287. 104. Khangura S, Konnyu K, Cushman R, Grimshaw J, Moher D. Evidence Summaries: The Evolution of a Rapid Review Approach. Syst.Rev. 2012;1:10,4053-1-10.

105. Buscemi N, Hartling L, Vandermeer B, Tjosvold L, Klassen TP. Single Data Extraction Generated More Errors than Double Data Extraction in Systematic Reviews. J.Clin.Epidemiol. 2006;59:697-703.

106. Ganann R, Ciliska D, Thomas H. Expediting Systematic Reviews: Methods and Implications of Rapid Reviews. Implement Sci. 2010;5:56,5908-5-56.

107. Rockhill B. The Privatization of Risk. Am.J.Public Health 2001;91:365-8.

108. Aral SO. Determinants of STD Epidemics: Implications for Phase Appropriate Intervention Strategies. Sex.Transm.Infect. 2002;78 Supp1 1:i3-13.

109. Rockhill B, Kawachi I, Colditz GA. Individual Risk Prediction and Population-Wide Disease Prevention. Epidemiol.Rev. 2000;22:176-80.

110. Falasinnu T, Gustafson P, Hottes TS, Gilbert M, Ogilvie G, Shoveller J. A Critical Appraisal of Risk Models for Predicting Sexually Transmitted Infections. Sex.Transm.Dis. 2014;41:321-30. 
Table 1: A summary of the criteria to be used to evaluate and rate the quality of methodology for each study*

\begin{tabular}{|c|c|}
\hline Element & Quality of methodology criteria \\
\hline A. Study design & $\begin{array}{l}\text { The study design was clearly evident (e.g., cross-sectional, cohort or case - } \\
\text { control). }\end{array}$ \\
\hline B. Specimen Collection & $\begin{array}{l}\text { The specimen collection methodology was clearly defined. If the same } \\
\text { specimen collection methodology was not used consistently among study } \\
\text { participants, methods to adjust for this difference were included in the } \\
\text { analyses. }\end{array}$ \\
\hline C. Statistical methods & $\begin{array}{l}\text { Multivariate analyses were used to examine the relationship between } \\
\text { predictors and STD outcome. Methods used to examine subgroups and } \\
\text { interactions were stated. }\end{array}$ \\
\hline D. Model selection & $\begin{array}{l}\text { A clear attempt at model selection was made. Step-wise procedures or an a } \\
\text { priori specification of p-value cutoff points for variable inclusion were } \\
\text { considered acceptable for this criterion. }\end{array}$ \\
\hline $\begin{array}{l}\text { E. Study sample } \\
\text { description }\end{array}$ & $\begin{array}{l}\text { The characteristics of the sample and the selection criteria for the study were } \\
\text { clearly stated such as: location, time period, sampling method, sample size, } \\
\text { entry criteria and exclusions. The study also included a description of non- } \\
\text { respondents. The extent and nature of missing data were assessed to estimate } \\
\text { potential bias. }\end{array}$ \\
\hline F. Variable definition & $\begin{array}{l}\text { Sources of data and details of methods of assessment were given for each } \\
\text { variable. }\end{array}$ \\
\hline G. Events per variable & $\begin{array}{l}\text { The final sample size that was actually used in the analysis comprised of } \geq 10 \\
\text { study outcomes per variable. }\end{array}$ \\
\hline H. Outcome assessment & $\begin{array}{l}\text { STD outcomes were measured by the most sensitive and specific tests } \\
\text { available at the time of data collection. }\end{array}$ \\
\hline I. Study generalizability & $\begin{array}{l}\text { STD screening was evaluated in an appropriate spectrum of subjects and } \\
\text { sampling was based upon a multi-center study or involved a single study with } \\
\text { a relatively large sample size of consecutive visits to a clinic. }\end{array}$ \\
\hline
\end{tabular}


Table 2: Comparison of risk factors listed in chlamydia and gonorrhea screening recommendations*

\begin{tabular}{|c|c|c|c|c|c|c|c|c|c|c|c|}
\hline \multirow[b]{2}{*}{ Organization** } & \multicolumn{11}{|c|}{ Risk factors } \\
\hline & $\begin{array}{l}\text { Younger } \\
\text { age }\end{array}$ & $\begin{array}{c}\text { Sexual } \\
\text { contact } \\
\text { of } \\
\text { STD } \\
\text { case }\end{array}$ & $\begin{array}{l}\text { Previous } \\
\text { STD }\end{array}$ & $\begin{array}{c}\text { New } \\
\text { sexual } \\
\text { partners }\end{array}$ & $\begin{array}{l}\text { Multiple } \\
\text { sexual } \\
\text { partners }\end{array}$ & $\begin{array}{l}\text { Drug or } \\
\text { alcohol } \\
\text { use }\end{array}$ & $\begin{array}{l}\text { Sex in } \\
\text { exchange } \\
\text { for money } \\
\text { or gifts }\end{array}$ & $\begin{array}{l}\text { Inconsistent } \\
\text { condom use }\end{array}$ & $\begin{array}{l}\text { Individuals or } \\
\text { travelers from } \\
\text { endemic } \\
\text { regions }\end{array}$ & $\begin{array}{c}\text { Street } \\
\text { involvement }\end{array}$ & $\begin{array}{l}\text { Sex with } \\
\text { anyone with } \\
\text { listed risk } \\
\text { factors }\end{array}$ \\
\hline US Preventive Services Task Force (USPSTF) & Yes & Yes & Yes & Yes & Yes & Yes & Yes & Yes & & & \\
\hline American Academy of Family Physicians (AAFP) & Yes & Yes & Yes & Yes & Yes & Yes & Yes & Yes & & & \\
\hline US Centers for Disease Control and Prevention (USCDC) & Yes & Yes & Yes & Yes & Yes & Yes & Yes & Yes & & & \\
\hline American Congress of Obstetricians and Gynecologists (ACOG)\# & Yes & Yes & Yes & & Yes & Yes & Yes & & Yes & & Yes \\
\hline Public Health Agency of Canada (PHAC) & Yes & Yes & Yes & Yes & Yes & Yes & Yes & & Yes & Yes & Yes \\
\hline European STD Guidelines (IUSTI Europe) & Yes & Yes & & Yes & Yes & & & Yes & & & \\
\hline British Association for Sexual Health and HIV (BASHH)\# & Yes & Yes & Yes & & Yes & Yes & & & Yes & & \\
\hline Australasian Society for HIV Medicine (ASHM) \# & Yes & & +8 & Yes & Yes & Yes & & & Yes & & \\
\hline
\end{tabular}

Australasian Society for HIV Medicine (ASHM)

*The following are American organizations: USPSTF, AAFP, USCDC, ACOG; the following are Canadian organizations: SOGC, PHAC; the following are European organizations: IUSTI, BASHH; and ASHM is an

Australian organization

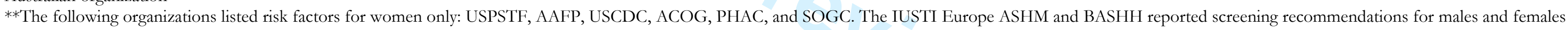

combined

\#Risk factors listed are for STIs in general, not just for chlamydia and gonorrhea 
Table 3: Percentage distribution of studies included in the literature review, by level of empirical support, according to selected characteristics

\begin{tabular}{|c|c|c|c|c|c|}
\hline Characteristic & $\mathrm{N}$ & Unacceptable $(\%)$ & Marginal $(\%)$ & Acceptable $(\%)$ & Commendable $(\%)$ \\
\hline \multicolumn{6}{|l|}{ STD } \\
\hline Chlamydia only & 51 & 9.8 & 25.5 & 39.2 & 25.5 \\
\hline Gonorrhea only & 6 & 0.0 & 33.3 & 66.7 & 0.0 \\
\hline Chlamydia and GC & 14 & 0.0 & 14.3 & 35.7 & 50.0 \\
\hline Other** & 4 & 0.0 & 25.0 & 50.0 & 25.0 \\
\hline \multicolumn{6}{|l|}{ Gender } \\
\hline Females only & 24 & 4.2 & 25.0 & 29.2 & 41.7 \\
\hline Males only & 15 & 20.0 & 26.7 & 33.3 & 20.0 \\
\hline Both (with stratification*) & 20 & 0.0 & 15.0 & 55.0 & 30.0 \\
\hline Both (without stratification) & 16 & 6.3 & 31.3 & 50.0 & 12.5 \\
\hline \multicolumn{6}{|l|}{ Country } \\
\hline Australia & 7 & 14.3 & 28.6 & 28.6 & 28.6 \\
\hline Italy & 3 & 0.0 & 33.3 & 0.0 & 66.7 \\
\hline Canada & 2 & 0.0 & 50.0 & 50.0 & 0.0 \\
\hline Netherlands & 3 & 0.0 & 0.0 & 0.0 & 100.0 \\
\hline Switzerland & 2 & 0.0 & 0.0 & 100.0 & 0.0 \\
\hline UK & 11 & 9.1 & 54.5 & 27.3 & 9.1 \\
\hline USA & 36 & 2.8 & 13.9 & 50.0 & 33.3 \\
\hline Other & 12 & 16.7 & 25.0 & 50.0 & 8.3 \\
\hline \multicolumn{6}{|l|}{ Setting } \\
\hline Population/registry & 16 & 0.0 & 25.0 & 43.8 & 31.3 \\
\hline Emergency room & 3 & 0.0 & 0.0 & 0.0 & 100.0 \\
\hline Sexual health clinic & 11 & 0.0 & 27.3 & 45.5 & 27.3 \\
\hline Family planning clinic & 5 & 0.0 & 40.0 & 40.0 & 20.0 \\
\hline GP clinic & 4 & 0.0 & 75.0 & 0.0 & 25.0 \\
\hline HIV study & 3 & 0.0 & 33.3 & 0.0 & 66.7 \\
\hline Military & 4 & 25.0 & 0.0 & 50.0 & 25.0 \\
\hline Detention facility & 11 & 9.1 & 9.1 & 63.6 & 18.2 \\
\hline Other & 18 & 16.7 & 22.2 & 44.4 & 16.7 \\
\hline \multicolumn{6}{|l|}{ Study design } \\
\hline Case control & 5 & 0.0 & 20.0 & 60.0 & 20.0 \\
\hline Cross sectional & 65 & 7.7 & 24.6 & 43.1 & 24.6 \\
\hline Prospective & 5 & 0.0 & 20.0 & 0.0 & 80.0 \\
\hline \multicolumn{6}{|l|}{ Presence of symptoms } \\
\hline Asymptomatic only & 6 & 0.0 & 66.7 & 16.7 & 16.7 \\
\hline Symptomatic and asymptomatic & 69 & 7.2 & 20.2 & 43.5 & 29.0 \\
\hline
\end{tabular}

* Reported separate stratified models or an interaction term

** Other includes combinations of Chlamydia, gonorrhea, syphilis and HIV outcomes 
Table 4: A summary of the level of empirical support for variables associated with STD outcomes according to the ratings of methodological quality

\begin{tabular}{|c|c|c|c|c|c|c|c|c|c|}
\hline & \multicolumn{8}{|c|}{ Proportion of studies (n) with significant findings according to ratings* } & \multirow[b]{3}{*}{ Level of empirical support } \\
\hline & \multicolumn{2}{|c|}{ Marginal } & \multicolumn{2}{|c|}{ Acceptable } & \multicolumn{2}{|c|}{ Commendable } & \multicolumn{2}{|c|}{ Total } & \\
\hline & $\mathrm{N}$ & $\%$ & $\mathrm{~N}$ & $\%$ & $\mathrm{~N}$ & $\%$ & $\mathrm{~N}$ & $\%$ & \\
\hline \multicolumn{10}{|l|}{ Underlying determinants } \\
\hline Age (at study time) & 20 & 55.0 & 44 & 59.1 & 20 & 85.0 & 84 & 64.3 & Strong evidence \\
\hline Age (at sexual debut) & 1 & 0.0 & 9 & 55.6 & 4 & 25.0 & 14 & 42.9 & Mixed evidence $\ddagger$ \\
\hline Race/Ethnicity & 10 & 70.0 & 37 & 67.6 & 18 & 72.2 & 65 & 69.2 & Moderate evidence \\
\hline Socio-economic status & 1 & 0.0 & 11 & 18.2 & 9 & 55.6 & 21 & 33.3 & Weak evidence \\
\hline Marital status & 3 & 100.0 & 10 & 20.0 & 4 & 25.0 & 17 & 35.3 & Weak evidence \\
\hline Drug/alcohol use & 7 & 0.0 & 12 & 33.3 & 3 & 33.3 & 22 & 22.7 & Weak evidence \\
\hline Sex in exchange for gifts/money & 2 & 0.0 & 6 & 16.7 & -- & -- & 8 & 12.5 & Weak evidence $\ddagger$ \\
\hline \multicolumn{10}{|l|}{ Proximate determinants } \\
\hline \multicolumn{10}{|l|}{ Exposure of susceptible to infected people } \\
\hline Multiple lifetime sexual partners & 1 & 100.0 & 7 & 57.1 & 9 & 100.0 & 17 & 82.4 & Strong evidence \\
\hline Multiple sex partners in recent months & 12 & 83.3 & 29 & 55.2 & 14 & 64.3 & 55 & 63.6 & Moderate evidence \\
\hline Sexual partners from overseas & 3 & 0.0 & 4 & 25.0 & 1 & 100.0 & 8 & 25.0 & Weak evidence $\ddagger$ \\
\hline Sex with regular partners & 4 & 25.0 & 3 & 33.3 & 3 & 0.0 & 10 & 20.0 & Weak evidence $\ddagger$ \\
\hline Sex with casual partners & 3 & 33.3 & 6 & 66.7 & 2 & 0.0 & 11 & 45.5 & Mixed evidence $\ddagger$ \\
\hline Sex with new partners & 5 & 100.0 & 9 & 22.2 & 10 & 60.0 & 24 & 54.2 & Mixed evidence \\
\hline Sex with infected partner & 4 & 100.0 & 12 & 75.0 & 6 & 100.0 & 22 & 86.4 & Strong evidence \\
\hline Sex with symptomatic partner & 1 & 100.0 & 5 & 80.0 & 5 & 100.0 & 11 & 90.9 & Strong evidence $¥$ \\
\hline \multicolumn{10}{|l|}{ Efficiency of transmission per contact } \\
\hline History of STI diagnosis & 7 & 57.1 & 22 & 45.5 & 12 & 33.3 & 41 & 43.9 & Weak evidence \\
\hline Concurrent STI diagnosis & 5 & 100.0 & 4 & 75.0 & 2 & 100.0 & 11 & 90.9 & Strong evidence $¥$ \\
\hline Condom use & 12 & 25.0 & 19 & 26.3 & 11 & 36.4 & 42 & 28.6 & Weak evidence \\
\hline
\end{tabular}

*Some articles were counted more than once if they conducted separate analysis by gender or STD

\#Insufficient research 


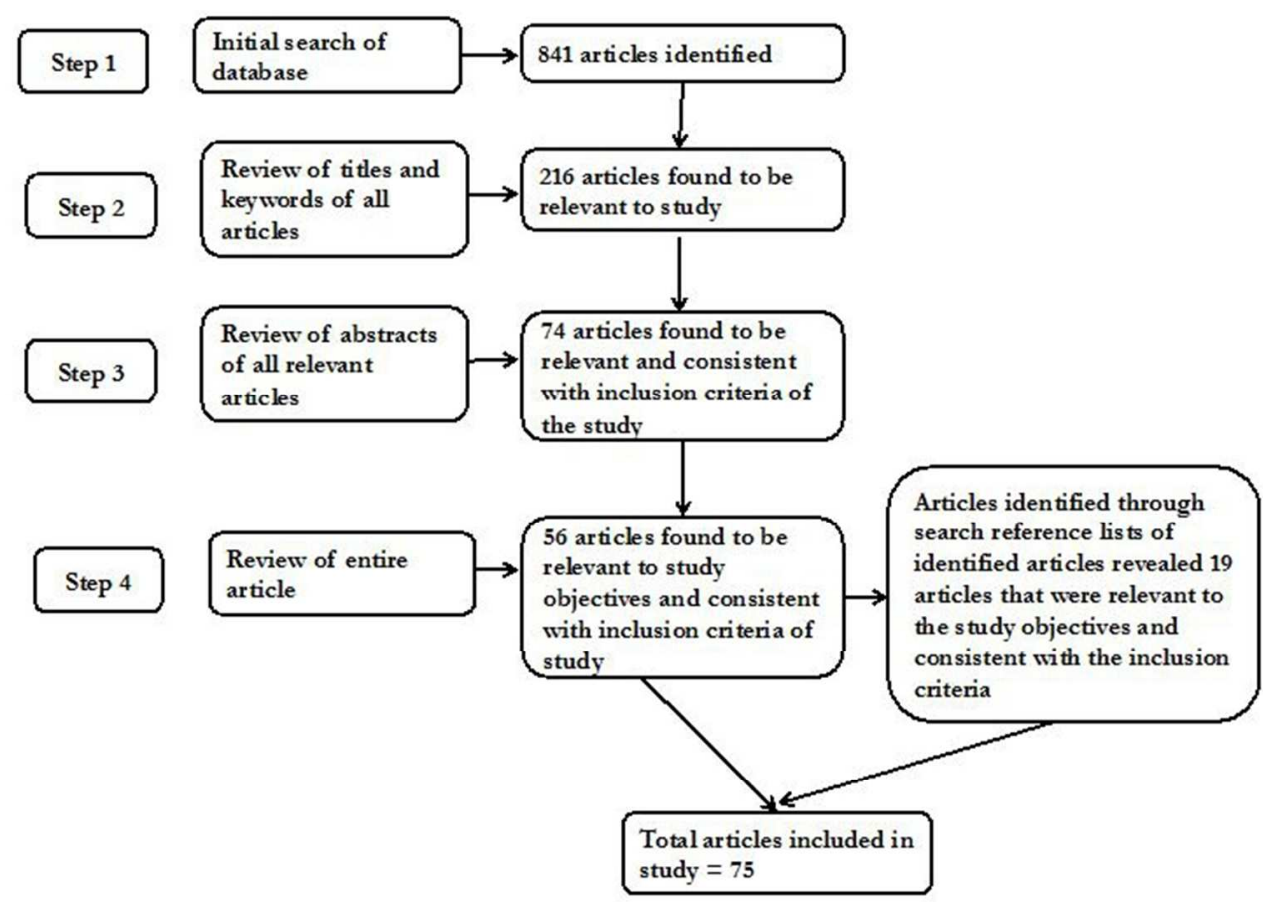

$196 \times 135 \mathrm{~mm}(96 \times 96 \mathrm{DPI})$ 
Figure 1: The process of selecting articles for the inclusion in the literature review of predictors of chlamydia and gonorrhea infection

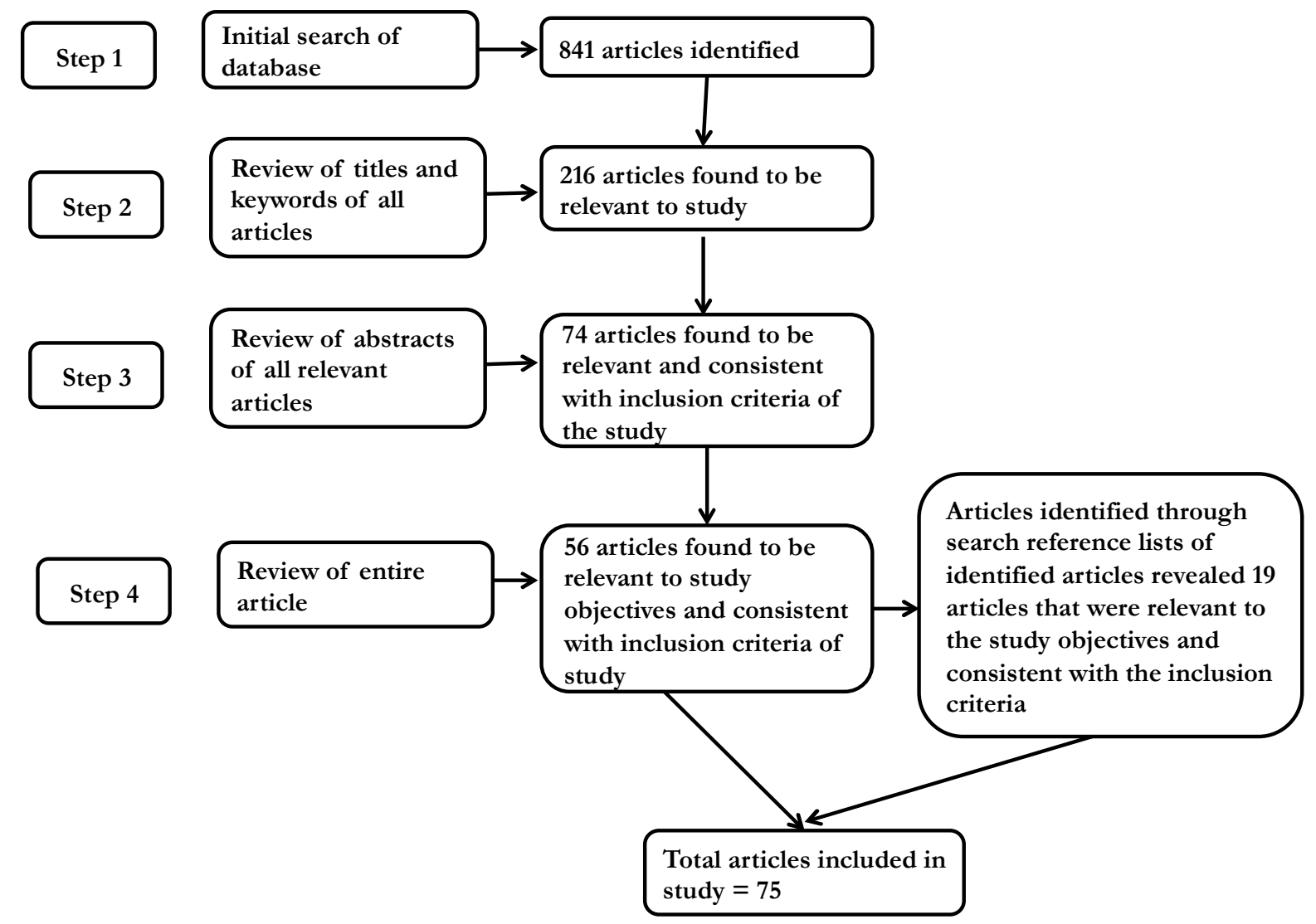

